\title{
Melanoma Arising from Blue Nevus
}

National Cancer Institute

\section{Source}

National Cancer Institute. Melanoma Arising from Blue Nevus. NCI Thesaurus. Code C4240.

A rare melanoma which develops in a pre-existing blue nevus. It occurs more frequently on the scalp, face, orbit, back, buttocks, extremities, hands, and feet. 